\title{
Kallikrein 12 downregulation reduces AGS gastric cancer cell proliferation and migration
}

\author{
X.S. $\mathrm{Li}^{1}$ and X.L. He ${ }^{2}$ \\ ${ }^{1}$ Chongqing Three Gorges Medical College, Chongqing, China \\ ${ }^{2}$ Chongqing Three Gorges Central Hospital, Chongqing, China \\ Corresponding author: X.L. He \\ E-mail: hexlctgch@163.com \\ Genet. Mol. Res. 15 (3): gmr.15038452 \\ Received January 15, 2016 \\ Accepted April 8, 2016 \\ Published August 29, 2016 \\ DOI http://dx.doi.org/10.4238/gmr.15038452 \\ Copyright (C) 2016 The Authors. This is an open-access article distributed under the terms of \\ the Creative Commons Attribution ShareAlike (CC BY-SA) 4.0 License.
}

\begin{abstract}
Abnormal expression of the kallikrein (KLK) family of serine proteases closely correlates with onset, progression, and prognosis of endocrine gland-related malignant tumors. The aim of this study was to evaluate how downregulation of KLK12 influenced cell cycle and proliferation of the AGS gastric cancer cell line. KLK12 was detected by western blot in GES-1 normal gastric epithelial and AGS cells. AGS cells were transfected with KLK12 siRNA, a negative control siRNA, or subjected to a mock transfection, following which, we assessed mRNA and protein levels, cell proliferation, cell migration, and cell cycle progression. We found that KLK12 levels were significantly higher in AGS cells than in GES-1 cells. Transfection of AGS cells with KLK12 siRNA led to downregulation of KLK12 mRNA and protein expression, reduced cell proliferation $(0.47 \pm 0.03$ vs $0.92 \pm 0.04, \mathrm{P}<0.01)$, and lower cell counts $\left(3.92 \pm 0.25 \times 10^{5} v s 5.47 \pm 0.50 \times 10^{5}, \mathrm{P}<0.01\right)$ with respect to the negative control. We observed that KLK12 siRNA increased the number of AGS cells in G0/G1 and reduced those in S phase. Furthermore, downregulation of KLK12 in AGS cells decreased
\end{abstract}


their ability to penetrate the membrane in a migration assay $(\mathrm{P}<0.05)$. In conclusion, KLK12 siRNA inhibited the proliferation and migration of AGS gastric cancer cells and caused their arrest in the G0/G1 phase of the cell cycle.

Key words: Kallikrein 12; Small interfering RNA; Cell proliferation; Cell cycle; Gastric cancer

\section{INTRODUCTION}

Human kallikreins (KLKs) form a polygenic family of serine proteases comprising 15 members. They are mainly present in tissues that produce or are regulated by steroid hormones (Tan et al., 2006; Angelopoulou and Karagiannis, 2015). Abnormal expression of KLKs such as KLK12 closely correlates with onset, progression, and prognosis of endocrine gland-related malignant tumors, such as breast, prostate, and ovarian cancers (Lose et al., 2012; Lai et al., 2014). RNA interference, also known as post-transcriptional gene silencing, uses RNA to bind specifically to mRNA inside cells and thus block or decrease translation of the target gene. Few studies have hitherto targeted KLK12 expression in this manner. Here, we evaluated the effect on growth after transiently transfecting gastric cancer cells with KLK12 siRNA.

\section{MATERIAL AND METHODS}

\section{Cell culture}

Normal gastric epithelial (GES-1) and gastric cancer (AGS) cell lines were purchased from the China Center for Type Culture Collection (Wuhan, China) and cultivated in RPMI 1640 medium at $37^{\circ} \mathrm{C}$ in a $5 \% \mathrm{CO}_{2}$ atmosphere.

\section{RNA interference}

AGS cells were cultivated for $24 \mathrm{~h}$ on plates and divided into three groups: KLK12 siRNA, negative control, and mock transfection control. Cells were incubated with $100 \mathrm{nM}$ KLK12 siRNA and liposomes (Dharmacon, Thermo Fisher Scientific, Waltham, MA, USA), control siRNA and liposomes, or RPMI 1640 medium at $37^{\circ} \mathrm{C}$ for $8 \mathrm{~h}$. Subsequently, the medium was changed and cells were incubated for another $48 \mathrm{~h}$. siRNA sequences were as follows: KLK12, sense strand 5'-AAACAGUGACAGCCACGUATT-3', anti-sense strand 5'-UACGUGGCUGUCACUGUUUGG-3'; negatice control, sense strand 5'-UUCUCCGAAC GUGUCACGUTT-3', anti-sense strand 5'-ACGUGACACGUUCGGAGAATT-3'. siRNAs were synthesized by Jiangsu Sainty Biotechnology (Jiangsu, China).

\section{RNA extraction, reverse transcription, and real-time fluorescence quantitative PCR (q-PCR)}

Total RNA was extracted using the Trizol method (Gibco BRL, Thermo Fisher Scientific), quality was assessed by formaldehyde electrophoresis, and the RNA was stored at $-20^{\circ} \mathrm{C}$. For reverse transcription, $5 \mu \mathrm{L}$ RNA was denatured at $70^{\circ} \mathrm{C}$ for $5 \mathrm{~min}$, followed by 
addition of $10 \mu \mathrm{L} 5 \mathrm{X}$ reverse transcription buffer, $2 \mu \mathrm{L}$ dNTPs, $0.5 \mu \mathrm{g}$ random primers, and 300 U M-MLV reverse transcriptase (Promega, Madison, WI, USA). The reaction proceeded at $42^{\circ} \mathrm{C}$ for $60 \mathrm{~min}$ and was terminated by increasing the temperature to $70^{\circ} \mathrm{C}$ for $10 \mathrm{~min}$. The PCR mix $(20 \mu \mathrm{L})$ contained $10 \mu \mathrm{L} 2 \mathrm{X}$ SYBR Green (TOYOBO, Osaka, Japan), $0.4 \mu \mathrm{L} 10$ pmol each of sense and anti-sense strands, $2 \mu \mathrm{L} \mathrm{cDNA}$, and deionized water. Primer sequences were as follows: KLK12, sense strand 5'-GCCTCAACCTCTCCATCGTC-3', anti-sense strand 5'-CTTGAAGGACTCCCCCACAC-3'; $\beta$-actin, sense strand 5'-CTGAGCAGATCATGAAG AC-3', anti-sense strand 5'-CTTGGTGGACGCATCCTGAG-3'. Primers were synthesized by Sangon Biotech Co., Ltd. (Shanghai, China). $\beta$-actin was used as internal control. Each sample was loaded in triplicate. Reaction conditions were as follows: $95^{\circ} \mathrm{C}$ for $1 \mathrm{~min} ; 95^{\circ} \mathrm{C}$ for $15 \mathrm{~s}$ and $60^{\circ} \mathrm{C}$ for $1 \mathrm{~min}$, for a total of 40 cycles. The fluorescence generated during gene amplification was detected in real-time (7500 FAST Real-time PCR System, Thermo Fisher). Relative mRNA expression was calculated by the $2^{-\Delta \Delta \mathrm{Ct}}$ method (Yin et al., 2015).

\section{Western blotting}

Total protein was extracted using a kit (Life Technologies, Thermo Fisher Scientific). Protein extracts $(400 \mu \mathrm{g})$ were separated by polyacrylamide gel electrophoresis, electrotransferred onto a membrane, and blocked overnight at $4^{\circ} \mathrm{C}$. Next, the membrane was incubated with mouse anti-human KLK12 antibody (1:750; Abcam, Cambridge, UK) at $25^{\circ} \mathrm{C}$ for $2 \mathrm{~h}$, with secondary antibody (1:2000, Santa Cruz) at room temperature for $1 \mathrm{~h}$, and finally developed by electrochemiluminescence (ThermoFisher, MD, USA).

\section{Cell proliferation assay}

Exponentially growing AGS cells were seeded on 96-well plates (5 x 103/well). Each condition was assayed in ten replicate wells. After transient transfection with KLK12 or negative control siRNA, cells were cultured for $48 \mathrm{~h}$ and then incubated in the presence of tetrazolium dye (MTT; Beyotime Institute of Biotechnology, Haimen, China) for $4 \mathrm{~h}$. Cells were resupended in $150 \mu \mathrm{L}$ DMSO and shaken at low speed for $15 \mathrm{~min}$. Absorbance at $490 \mathrm{~nm}$ was measured using an enzyme-linked immunosorbent assay reader.

\section{Cell counting}

AGS cells were seeded on 24-well plates at a density of $5 \times 10^{4}$ cells/well. Each condition was assayed in triplicate. Cells were transfected with either KLK12 or negative control siRNA, cultured for $48 \mathrm{~h}$, and counted with a Coulter counter (Beckman Coulter, Brea, CA, USA).

\section{Cell cycle analysis}

AGS cells were seeded on 6-cm culture dishes $\left(4 \times 10^{5} / \mathrm{mL}\right)$. Twenty-four hours after inoculation, they were transiently transfected with either KLK12 or negative control siRNA, cultured for another $48 \mathrm{~h}$, washed with phosphate-buffered saline, fixed in $70 \%$ ethanol, and stained with propidium iodide solution containing 0.01\% RNase (Beyotime Institute of Biotechnology) in the dark at $4^{\circ} \mathrm{C}$ for $30 \mathrm{~min}$. Cell cycle progression was measured by flow cytometry (FACScan flow cytometer, Becton Dickinson, Mountain View, CA, USA).

Genetics and Molecular Research 15 (3): gmr.15038452 


\section{Cell migration assay}

The migratory properties of AGS cells were assessed using the CytoSelect 24-Well Cell Migration Assay Combo Kit (Cell Biolabs, San Diego, CA, USA). Cells were seeded on 24-well plates and incubated at room temperature for $10 \mathrm{~min}$. After the density was adjusted to $1 \times 10^{6} / \mathrm{mL}$, cells were resuspended in serum-free culture medium. Culture medium $(500 \mu \mathrm{L})$ containing $10 \%$ fetal bovine serum was added to the lower chamber of 24 -well plates and 300 $\mu \mathrm{L}$ cell suspension was added to the inside of each insert. Cells were cultured for $24 \mathrm{~h}$ in an incubator. At this point, non-migrating cells were removed with 2-3 damp cotton swabs. The remaining cells were transferred to sterile culture plates, stained with $400 \mu \mathrm{L} 0.09 \%$ crystal violet solution, gently rinsed in water three times, air-dried, and observed under a microscope. Cells' migratory ability was assessed by counting the cells that penetrated the membrane insert in the upper, middle, lower, left, and right visual fields.

\section{Statistical analysis}

All data were analyzed by the SPSS 13.0 software (SPSS Inc., Chicago, IL, USA) and reported as means \pm SD. Multi-group comparisons were performed by one-way analysis of variance. Pairwise comparisons were conducted using the chi-square test. $\mathrm{P}<0.05$ was considered statistically significant.

\section{RESULTS}

\section{KLK12 level in AGS and GES-1 cells}

Western blotting showed that KLK12 was significantly higher in AGS than in GES-1 cells (Figure 1).

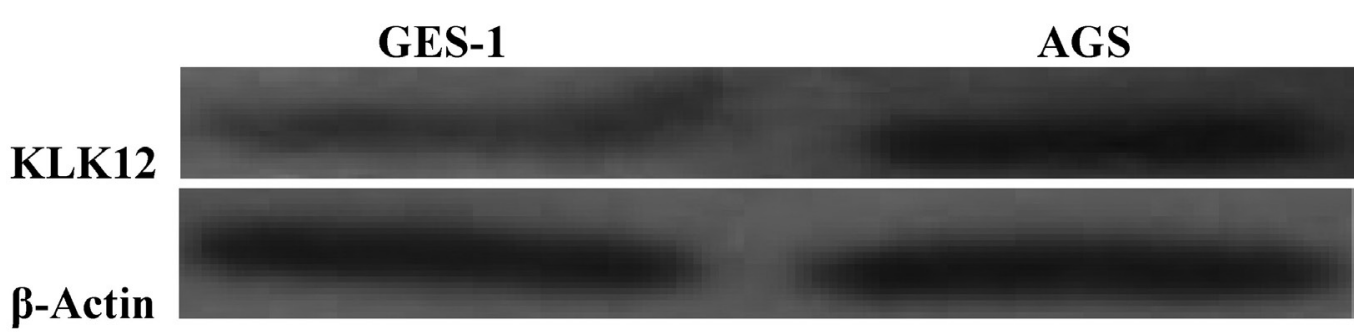

Figure 1. KLK12 protein expression in GES-1 and AGS cells.

\section{KLK12 siRNA reduces KLK12 and KLK12 levels}

qPCR showed that $K L K 12$ mRNA expression did not change significantly in negative and blank control groups; however, it decreased markedly in AGS cells transfected with KLK12 siRNA ( $\mathrm{P}<0.05$; Figure 2$)$. The same cells produced significantly less KLK12 than the two control groups $(\mathrm{P}<0.05)$, for which values were very similar (Figure 3 ). 


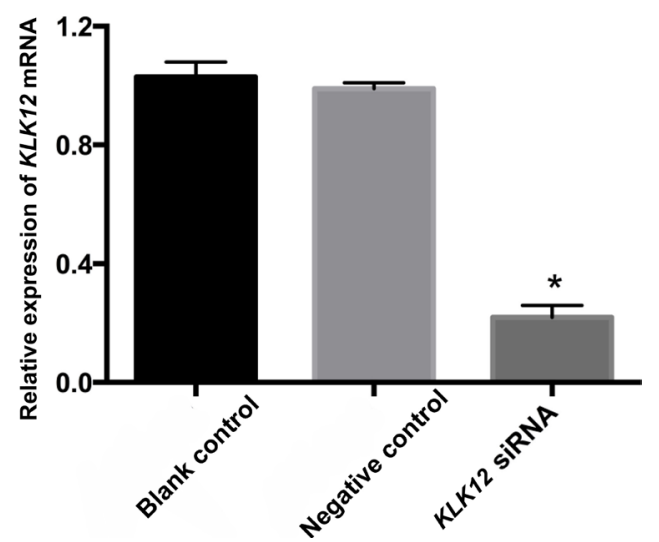

Figure 2. KLK12 mRNA expression in AGS cells transfected with $K L K 12$ siRNA. $* \mathrm{P}<0.05$ vs blank control and negative control groups.
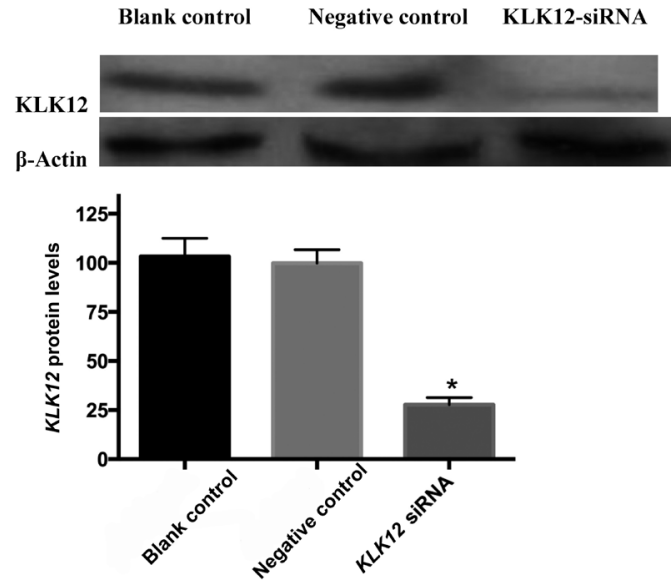

Figure 3. KLK12 protein expression in AGS cells transfected with KLK12 siRNA. ${ }^{*} \mathrm{P}<0.05$ vs blank control and negative control groups.

\section{Downregulation of $K L K 12$ retards AGS cell proliferation}

Absorbance values from the MTT assay were $0.47 \pm 0.03$ and $0.92 \pm 0.04$ for the $K L K 12$ siRNA and negative control groups, respectively. Values were significantly different $(\mathrm{P}<0.01)$. There were $(3.92 \pm 0.25) \times 10^{5}$ and $(5.47 \pm 0.50) \times 10^{5}$ cells in the KLK12 siRNA and negative control groups, respectively, with the former displaying significantly slower proliferation $(\mathrm{P}<0.01)$.

\section{Effect of KLK12 siRNA on cell cycle}

Compared with the negative control group, significantly more KLK12 siRNAtransfected cells were in $\mathrm{G} 0 / \mathrm{G} 1$ and fewer were in $\mathrm{S}$ phase $(\mathrm{P}<0.05$; Figure 4$)$. Cell cycle distribution was not significantly affected. 

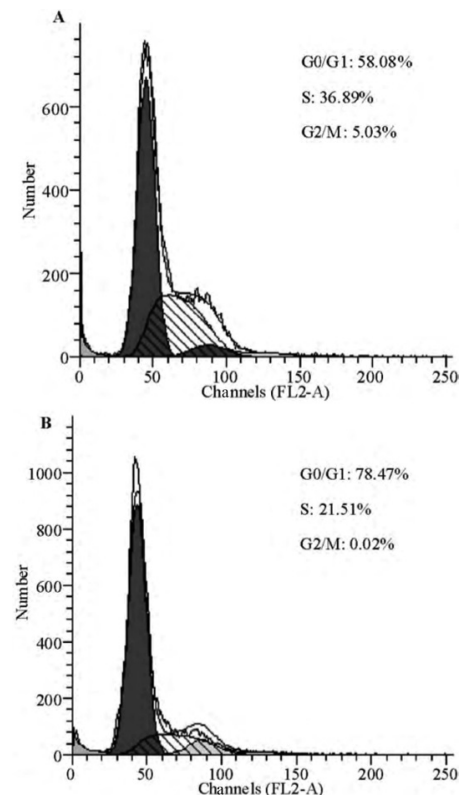

Figure 4. Effect of KLK12 siRNA transfection on cell cycle. A. Negative control group; B. KLK12 siRNA group.

\section{Downregulation of $K L K 12$ impairs AGS cell migration}

In the cell migration assay, membrane-penetrating AGS cells were stained blue. The number of cells penetrating the membrane in the blank (38.47 \pm 3.22$)$ and negative (41.14 \pm 2.12 ) control groups was significantly higher than that in the KLK12 siRNA group (17.87 $\pm 2.31)(\mathrm{F}=644.059, \mathrm{P}=0.000$; Figure 5). Therefore, we concluded that KLK12 siRNA significantly weakened in vitro migratory ability.

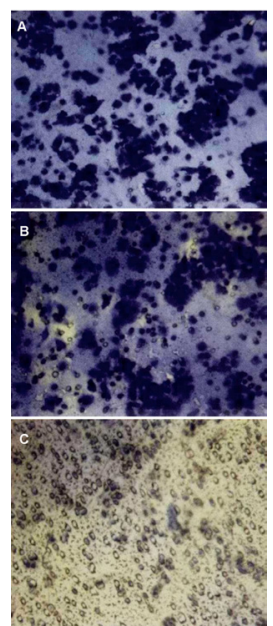

Figure 5. Effect of $K L K 12$ siRNA transfection on cell migration (200X magnification). A. Blank control group; B. negative control group; C. KLK12 siRNA group. 


\section{DISCUSSION}

Human KLK genes, located on chromosome 19q13.3-13.4, include 15 closely linked members that do not interfere with other genes. KLK1-KLK15 represent the largest gene cluster of proteases in the human genome (Sukumar et al., 2014; Kalinska et al., 2016). KLKs are abnormally expressed in prostate, ovarian, breast, and testicular cancers, indicating that they play important roles in the onset and progression of endocrine tumors. Moreover, KLKs have been recently detected in tumors of the digestive system. Nagahara et al. (2005) have reported that $K L K 6$ was highly expressed in gastric cancer tissues from 66 patients. Downregulation of $K L K 6$ by siRNA weakened proliferative capacity, cell cycle progression, and invasiveness of the MKN28 gastric cancer cell line. Feng et al. (2006) examined samples from 63 colorectal and 36 gastric cancer patients by RT-PCR, western blotting, and immunohistochemical staining. They observed that the transcriptional and translational levels of KLK10 in tumor tissues significantly exceeded those of normal ones. In addition, KLK10 overexpression in HCT116, HT29, CoLo205, LoVo, and AGS cell lines indicates a close link between KLK10 and the onset of tumors in the digestive system. Moreover, Huang et al. (2007) reported that KLK10 overexpression in patients with gastric cancer indicated poor prognosis. We have previously found that KLK12 expression was higher in gastric cancer tissues compared to that in normal gastric mucosae, especially in poorly differentiated adenocarcinomas (Zhao et al., 2012). Taken together, these findings suggest that blocking KLK12 expression in gastric cancer cells may inhibit their growth and progression, representing a promising target for future therapy.

As a novel gene disruption technique, exogenous and endogenous RNA interference can specifically and efficiently suppress gene expression at the post-transcriptional level. Within a short time, it has been used in various applications as a potent gene therapy tool (Xiao and Deng, 2009; Lorenzer et al., 2015). Here, KLK12 expression in AGS cells was significantly downregulated by RNA interference. As evidenced by the MTT assay and cell cycle analysis, downregulation of KLK12 expression significantly inhibited proliferation by arresting cells in G0/G1 phase. During normal cell growth there is a slight risk of the DNA becoming damaged. If left unrepaired, such DNA may substantially destabilize the genome, resulting in cells becoming cancerous or directly participating in tumor onset and progression (Zhou and Elledge, 2000; Bohr et al., 2007; Hoeijmakers, 2007).

Having previously investigated the role of KLK12 in MKN and SGC gastric cancer cell lines (Zhao et al., 2012), here we turned our attention to AGS cells. Although we observed that $K L K 12$ had a similar effect on cell proliferation and migration in all three cell lines, AGS cells displayed a lower degree of differentiation in the S phase (Ran et al., 2004). This is of relevance considering that Helicobacter pylori can easily adhere to and invade human gastric epithelial cells. It has been shown that infection with low-density $H$. pylori modified proliferation and apoptosis of AGS cells (Ito et al., 2008).

A decrease in KLK12 levels significantly inhibited migration of AGS cells. Hence, KLK12 may promote the growth of gastric cancers, probably by transcriptionally regulating essential genes related to cell proliferation and cell cycle progression, as well as by affecting cellular behavior. Further studies on the downstream regulatory mechanisms of KLK12 would be of great significance.

\section{Conflicts of interest}

The authors declare no conflict of interest.

Genetics and Molecular Research 15 (3): gmr.15038452 


\section{REFERENCES}

Angelopoulou K and Karagiannis GS (2015). Identification, molecular characterization and alternative splicing of three novel members of the canine kallikrein (Klk)-related peptidase family. Anticancer Res. 35: 2715-2723.

Bohr VA, Ottersen OP and Tønjum T (2007). Genome instability and DNA repair in brain, ageing and neurological disease. Neuroscience 145: 1183-1186. http://dx.doi.org/10.1016/j.neuroscience.2007.03.015

Feng B, Xu WB, Zheng MH, Ma JJ, et al. (2006). Clinical significance of human kallikrein 10 gene expression in colorectal cancer and gastric cancer. J. Gastroenterol. Hepatol. 21: 1596-1603. http://dx.doi.org/10.1111/j.14401746.2006.04228.x

Hoeijmakers JH (2007). Genome maintenance mechanisms are critical for preventing cancer as well as other agingassociated diseases. Mech. Ageing Dev. 128: 460-462. http://dx.doi.org/10.1016/j.mad.2007.05.002

Huang W, Zhong J, Wu LY, Yu LF, et al. (2007). Downregulation and CpG island hypermethylation of NES1/hK10 gene in the pathogenesis of human gastric cancer. Cancer Lett. 251: 78-85. http://dx.doi.org/10.1016/j.canlet.2006.11.006

Ito K, Yamaoka Y, Ota H, El-Zimaity H, et al. (2008). Adherence, internalization, and persistence of Helicobacter pylori in hepatocytes. Dig. Dis. Sci. 53: 2541-2549. http://dx.doi.org/10.1007/s10620-007-0164-z

Kalinska M, Meyer-Hoffert U, Kantyka T and Potempa J (2016). Kallikreins - The melting pot of activity and function. Biochimie 122: 270-282. http://dx.doi.org/10.1016/j.biochi.2015.09.023

Lai J, An J, Nelson CC, Lehman ML, et al. (2014). Analysis of androgen and anti-androgen regulation of KLK-related peptidase 2, 3, and 4 alternative transcripts in prostate cancer. Biol. Chem. 395: 1127-1132.http://dx.doi.org/10.1515/ hsz-2014-0149

Lorenzer C, Dirin M, Winkler AM, Baumann V, et al. (2015). Going beyond the liver: progress and challenges of targeted delivery of siRNA therapeutics. J. Control. Release 203: 1-15.http://dx.doi.org/10.1016/j.jconrel.2015.02.003

Lose F, Srinivasan S, O’Mara T, Marquart L, et al.; Australian Prostate Cancer BioResource (2012). Genetic association of the KLK4 locus with risk of prostate cancer. PLoS One 7: e44520.http://dx.doi.org/10.1371/journal.pone.0044520

Nagahara H, Mimori K, Utsunomiya T, Barnard GF, et al. (2005). Clinicopathologic and biological significance of kallikrein 6 overexpression in human gastric cancer. Clin. Cancer Res. 11: 6800-6806. http://dx.doi.org/10.1158/1078-0432. CCR-05-0943

Ran ZH, Liu J, Feng Y, Zou J, et al. (2004). Investigation of the sensitivities of distinct gastric cancer cells to parvovirus H-1 induced cytotoxicity. Chin. J. Dig. Dis. 5: 93-97. http://dx.doi.org/10.1111/j.1443-9573.2004.00163.x

Sukumar N, Scott E, Dimitromanolakis A, Misiak A, et al. (2014). Mining for single nucleotide variants (SNVs) at the kallikrein locus with predicted functional consequences. Biol. Chem. 395: 1037-1050. http://dx.doi.org/10.1515/ $\underline{\text { hsz-2014-0136 }}$

Tan OL, Whitbread AK, Clements JA and Dong Y (2006). Kallikrein-related peptidase (KLK) family mRNA variants and protein isoforms in hormone-related cancers: do they have a function? Biol. Chem. 387: 697-705.http://dx.doi. org/10.1515/BC.2006.088

Xiao J and Deng C (2009). Knockdown of Bmi-1 impairs growth and invasiveness of human gastric carcinoma cells. Oncol. Res. 17: 613-620.http://dx.doi.org/10.3727/096504009789745502

Yin Q, Fischer L, Noethling C and Schaefer WR (2015). In vitro-assessment of putative antiprogestin activities of phytochemicals and synthetic UV absorbers in human endometrial Ishikawa cells. Gynecol. Endocrinol. 31: 578581.http://dx.doi.org/10.3109/09513590.2015.1047448

Zhao EH, Shen ZY, Liu H, Jin X, et al. (2012). Clinical significance of human kallikrein 12 gene expression in gastric cancer. World J. Gastroenterol. 18: 6597-6604.http://dx.doi.org/10.3748/wjg.v18.i45.6597

Zhou BB and Elledge SJ (2000). The DNA damage response: putting checkpoints in perspective. Nature 408: 433-439. http://dx.doi.org/10.1038/35044005

Genetics and Molecular Research 15 (3): gmr.15038452 